\title{
Bärentraube gegen Blasenkeime
}

— Schon seit dem Mittelalter vertrauen die Menschen bei Entzündungen der Blase auf die heilende Wirkung der Bärentraube, deren Wirkstoff Arbutin mittlerweile gut erforscht ist. Seit 1994 ist die antibakterielle Wirkung von Bärentraubenblättern auch durch das Bundesgesundheitsamt offiziell bestätigt und die Anwendung bei entzündlichen Erkrankungen der ableitenden Harnwege anerkannt. Mit Cystinol akut ${ }^{\circledR}$ steht ein Bärentraubenblätter-Präparat zur Verfügung, das aufgrund des streng kontrollierten Herstellungsverfahrens in jedem Dragee die exakt gleiche Menge Arbutin enthält. Bei unkomplizierten Harnwegsinfekten können solche Bärentraubenblätter-Präparate die Anwendung von Antibiotika häufig ersetzen. Nach der Einnahme von Cystinol akut ${ }^{\circledR}$ wird das Arbutin zunächst zu Hydrochinonverbindungen umgewandelt, welche über den Urin ausgeschieden werden. Die Bakterien im Urin wiederum, die den Infekt verursacht haben, nehmen diese Verbindungen auf und spalten sie zu freiem Hydrochinon, dem aktiven Wirkstoff in Cystinol akut ${ }^{\oplus}$. Der Wirkstoff wird also erst in den Bakterien freigesetzt, was bedeutet, dass die Wirksamkeit nicht vom ph-Wert des Urins abhängig ist. Begleitend zur Einnahme ist daher weder eine Nahrungsumstellung noch die Gabe von Natriumhydrogencarbonat zur Alkalisierung des Urins erforderlich.
Bärentraubenblätter können außerdem bei der Diagnose "Reizblase" eingesetzt werden - hier in Kombination mit Echtem Goldrutenkraut (Cystinol ${ }^{\oplus}$ N Lösung). Dazu gibt es seit Kurzem den Patientenratgeber „Frauenthema Reizblase”, den Ärzte kostenlos anfordern können - per E-Mail an service@cystinol.de beziehungsweise per Post an Schaper \& Brümmer, Cystinol ${ }^{{ }_{-}}$ Serviceteam, Stichwort: Ratgeber, Bahnhofstr. 35, 38259 Salzgitter.

Nach Informationen von Schaper \&

Brümmer, Salzgitter-Ringelheim

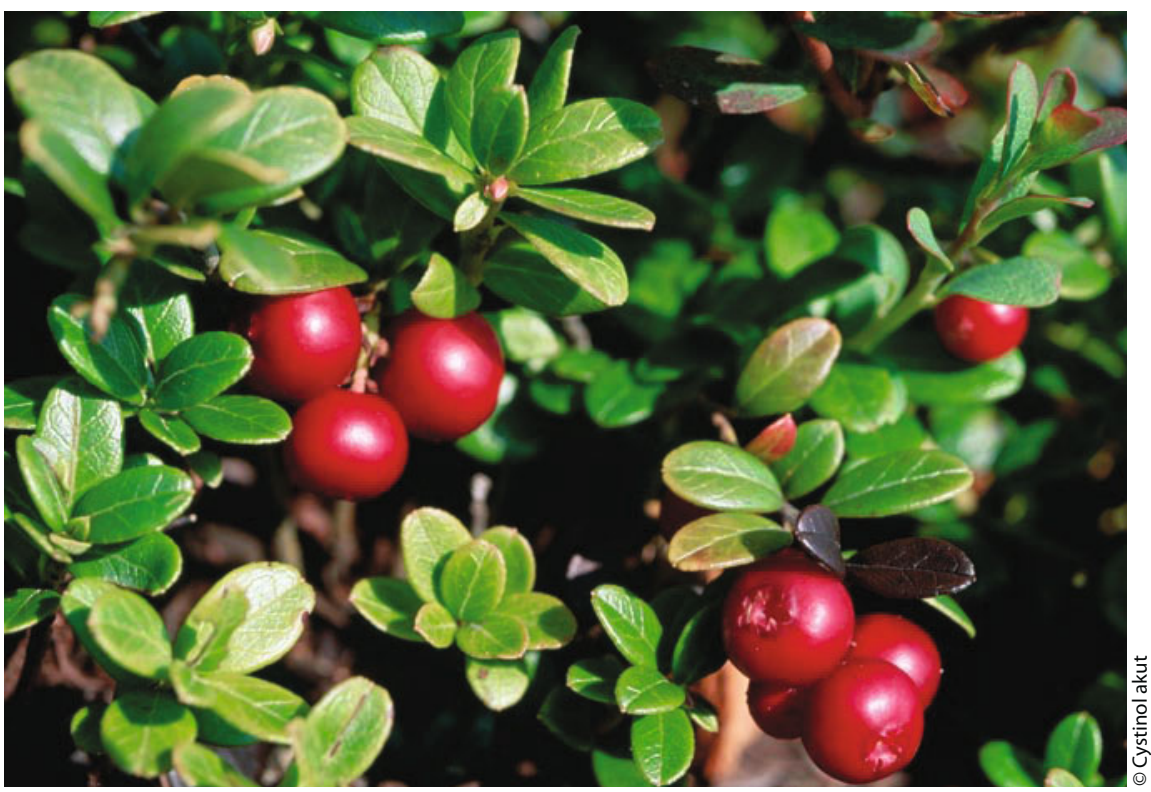

Der Wirkstoff aus den Bärentraubenblättern kann eine Antibiotikagabe bei unkomplizierten Harnwegsinfekten überflüssig machen.

\section{Testosteronmangelsyndrom - Erektile Dysfunktion als Indikator}

— Der erste Deutsche Männergesundheitsbericht der Stiftung Männergesundheit und der Deutschen Gesellschaft für Mann und Gesundheit hat erneut bestätigt: Deutschlands Männer achten zu wenig auf die eigene Gesundheit. Insbesondere die so genannten Aging-Male-Symptome - hormonelle Veränderungen bei Männern über 40 - werden in der urologischen Praxis wenig thematisiert. Klinische Symptome eines Testosteronmangels beim Altershypogonadismus sind sexuelle Funktionsstörungen in Form einer Erektilen Dysfunktion (ED) und die Verminderung morgendlicher Erektionen oder des sexuellen Verlangens (Libidoverlust)., Schon bei einem Testosteron-Serumspiegel von 8,5 nmol/I tritt eine ED signifikant häufiger auf", erläutert Professor Hermann M. Behre, Halle.
Eine Bestimmung des Testosteronspiegels im Serum sei daher im Rahmen der klinischen Diagnostik einer ED empfohlen. Bei Patienten mit einem Testosteronmangel und einer ED oder Libidoverlust sei daher das rationale Behandlungskonzept die Testosteronersatztherapie.

Allgemein ist bei Werten unterhalb von $8 \mathrm{nmol} / \mathrm{l}$ nach zweimaliger Messung des Serumtestosteronspiegels eine Testosteronsubstitution zum Beispiel mit dem TestosterongelTestim ${ }^{\circledast}$ indiziert. Im Grenzbereich von $8 \mathrm{nmol} / \mathrm{l}$ bis $12 \mathrm{nmol} / \mathrm{l}$ besteht Handlungsbedarf, wenn Symptome vorliegen. Laut Professor Aksam A. Yassin, Norderstedt, habe das Präparat Testim ${ }^{\circledast}$ gezeigt, dass es im Vergleich zu anderen Gelformulierungen höhere Testosteronspiegel im Blut erreichen kann - und das ohne höheres Nebenwirkungsprofil.

Einen Patientenratgeber zum Thema, der erklärt welche körperlichen und psychischen Veränderungen möglicherweise durch einen Testosteronmangel verursacht werden können und was man dagegen tun kann, können Ärzte kostenlos anfordern bei: Ferring Arzneimittel GmbH, Fabrikstr. 7, 24103 Kiel. Zudem bietet die Website www.männergerecht.de vielfältige Informationen rund um das Thema Männergesundheit, unter anderem steht ein Testosteron-Check zur schnellen Selbsteinschätzung der Testosteronwerte zur Verfügung.

Nach Informationen von Ferring, Kiel 